\section{Santa Comba de Bande (Orense). Arquitectura y documentación escrita}

Luis Caballero, Fernando ArCe, M. a de los Ángeles Utrero Unidad Asociada CSIC/Universidad del País Vasco. Grupo de Arqueología Tardoantigua y Medieval. Arqueología de la Arquitectura (GATMAA)

\begin{abstract}
Resumen
La aplicación del método estratigráfico al estudio de la arquitectura está suponiendo, en no pocos casos, entrar en conflicto con las ideas tradicionales vigentes en cada caso. Santa Comba de Bande es un ejemplo de ello. La lectura acrítica de un documento procedente del cercano monasterio de Celanova sirvió en su momento para trazar un guión sobre el origen y evolución del templo que ha marcado profundamente los diferentes acercamientos al edifico a lo largo de más de un siglo de investigación. Los resultados del análisis de paramentos evidencian una serie de contradicciones entre la noticia textual y la realidad material que obligan a relativizar el valor del documento en cuestión como fuente de información fidedigna así como evidenciar los peligros que entraña, en la interpretación arqueológica, partir de ideas apriorísticas.
\end{abstract}

Palabras clave: Estratigrafía; apriorismo; documento; Bande; Alfonso III.

\begin{abstract}
The application of the stratigraphic method to the study of architecture implies, in more than a few cases, arguing against the traditional ideas in place in each case. Santa Comba de Bande is one example of this. The uncritical reading of a document from the nearby monastery of Celanova was first used to sketch an idea of the origin and evolution of the temple that has profoundly marked the various approaches to the building during more than a century of research. The results from the analysis of facings show a series of contradictions between the contents of the document and material reality, which makes it necessary to relativize the value of the document in question as a source of reliable information, while also showing the dangers involved in working from aprioristic principles in archaeological interpretation.
\end{abstract}

Key words: Stratigraphy; apriorism; document; Bande; Alfonso III.

\section{UN GUIÓN DOCUMENTAL PARA UNA HISTORIA}

La historia constructiva de Santa Comba de Bande se ha explicado tradicionalmente gracias a la información ofrecida por un documento escrito. Según el atractivo guión de este texto, redactado en la primera mitad del siglo XVII y que recoge e interpreta diversas informaciones antiguas, la iglesia de Santa Comba es de origen visigodo, se abandona como consecuencia del "cataclismo» islámico y se repara por personajes relacionados con el poder asturiano dos centurias después.

Este guión fue asumido sin fisuras por los estudiosos, haciendo de la iglesia un modelo de la edilicia visigoda definido por el aparejo de sillería, el abovedamiento completo, la planta cruciforme rodeada de habitaciones, la decoración escultórica y el arco de herradura en la entrada del ábside. Trabajos como los de Camps (1963 (1935): 589-98) o Schlunk (1947: 285-89) venían a confirmar estos caracteres pertenecientes al periodo visigodo. Solamente la opinión de Puig (1961: 137) y Camón (1963: 214) se desmarcan de la teoría consensuada criticando el valor cronológico del documento escrito y situando la iglesia a finales del siglo IX y principios del $\mathrm{X}$.

Dentro de la teoría tradicional, cuando se hallaron contradicciones, se pretendieron explicar acomodándose a este guión. De esta manera, se intentó demostrar la reparación del edificio que citaba el documento apoyándose en los argumentos tipológicos que consideran las bóvedas de ladrillo y una pareja de los capiteles de la embocadura del ábside propios del siglo IX. Palol (1968: 148-50) considera que el friso y, consecuentemente, las bóvedas serían mozárabes. En la misma línea, debemos situar los estudios de Núñez (1978: 86ss), Kingsley (1980: 183ss) y Caballero (1980; 1991). Los dos últimos, con diferentes argumentos, encuentran la restauración del documento en la sustitución de un supuesto ábside anterior por el actual.

\section{EL EDIFICIO ORIGINAL:UNIDAD DE LOS ALZADOS Y PLANTA EN CRUZ EXENTA}

El análisis estratigráfico de la iglesia fue solicitado por los arquitectos, dada su importancia y singularidad, y motivado por la restauración de sus cubiertas. Una vez realizada la fotogrametría detallada del edificio, se procedió a la lectura de paramentos. Desde el punto de vista histórico, la principal pregunta a resolver era si había dos edificios altomedievales, como se ha justificado hasta ahora con la documentación escrita, o si había una única iglesia original.

Etapa I. Iglesia original. La estratigrafía descubre que la fábrica original se conserva en gran parte desde los cimientos a las bóvedas y desde el ábside hasta el porche. No se reco- 

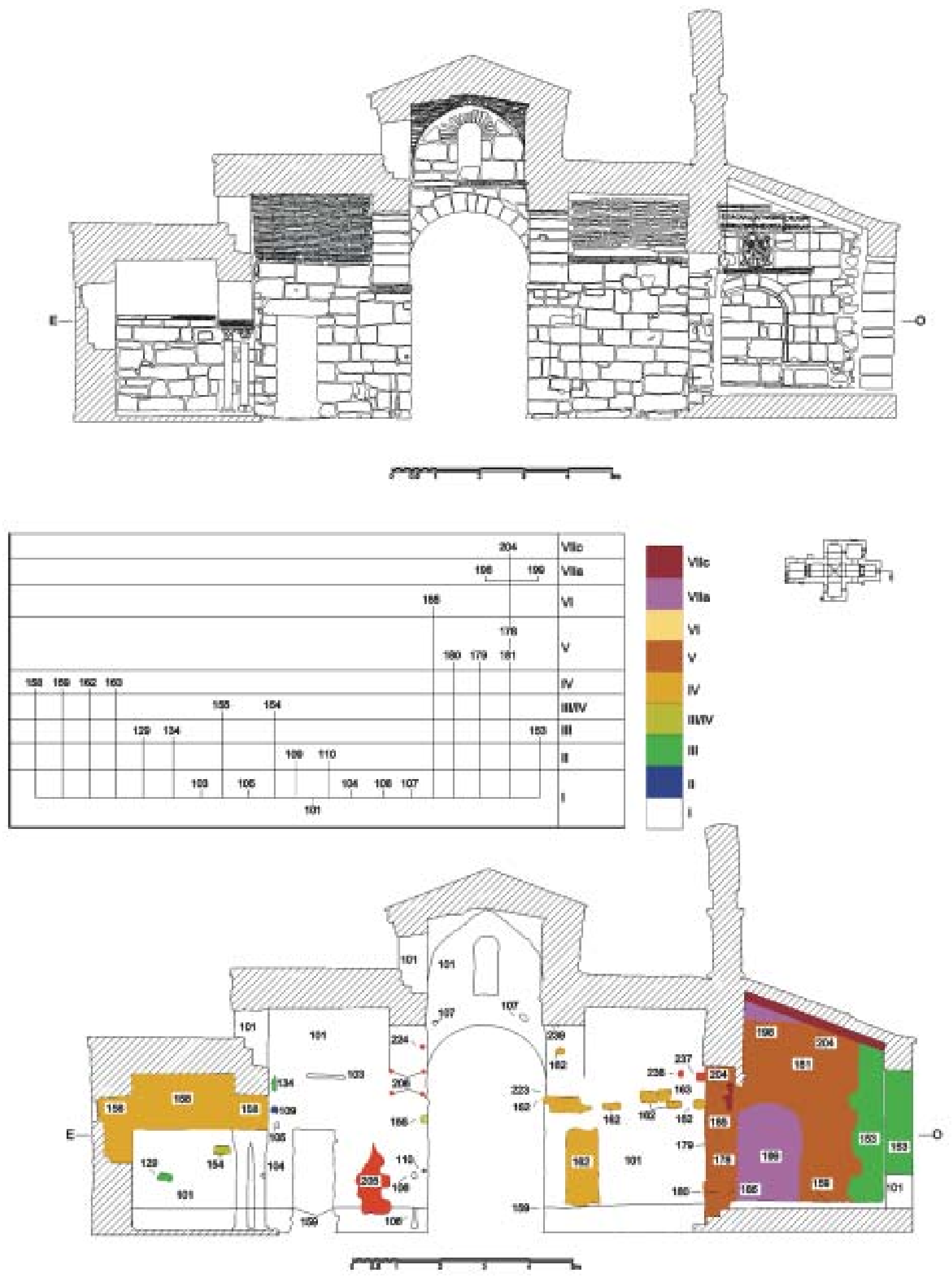

Fig. 1. Lectura de la sección E-O hacia el Sur 
nocen soluciones de continuidad ni entre el ábside y el anteábside, ni entre los muros de sillería y las bóvedas de ladrillo (Fig. 1).

Aunque posteriormente se acometió la reconstrucción de diferentes partes de los lienzos exteriores de los muros derruidos a causa del empuje de las bóvedas, como de las hojas exteriores de las naves del crucero y de la nave de los pies, y se realizaron varios añadidos, como las estancias en las esquinas entre las naves, todas estas actuaciones no afectaron sustancialmente al aspecto original de la iglesia. El uso ininterrumpido no alteró ni la planta ni el alzado de la construcción.

La propuesta de dos iglesias altomedievales consecutivas, se ve además discutida por otros resultados importantes. La lectura demuestra que el ábside y el anteábside son coetáneos, como indican la unidad de aparejo, la ausencia de cortes y los enjarjes interiores de los muros mediante sillares doblados. Por otro lado, las habitaciones laterales delanteras parecen corresponder a un segundo momento, como demuestran los mechinales tallados irregular y posteriormente en el muro sur del anteábside y la ausencia de una cubierta abovedada, y el porche es de época original, coincidiendo los cimientos con los del actual, rehecho en un momento posterior. Obtendríamos así una planta cruciforme exenta con porche.
Etapa II. Época alto medieval. Primera ruina y habitaciones delanteras. La ruina de la primera iglesia obliga a reconstruir el testero de la nave norte, hecho que facilita el enjarje de la habitación lateral delantera. La secuencia pudo ser similar en el lado sur. En este momento, tuvo lugar posiblemente la adición de las habitaciones traseras y la primera reconstrucción del porche. Por último, se abre un «altar nicho» en el muro oriental del crucero sur, análogo a las ventanas orientales del crucero.

Etapas III y IV. Época medieval. La ausencia de los enjarjes de la habitación delantera sur en la esquina correspondiente de la nave del crucero implica que los paramentos externos de ésta se reconstruyeron posteriormente a la construcción de la habitación. Lo mismo ocurrió posiblemente en el lado norte. Esta observación también significa una nueva ruina en el edificio, que posiblemente arrastró con ella las habitaciones. Entre otras reformas efectuadas en este momento, destacamos la instalación de un sobrado en la nave norte, lo que conllevó el cierre de la puerta oeste de la nave citada

A finales de la Edad Media (Etapa IV), se colocó un coro alto a los pies, se elevó el suelo y se pintó de nuevo el interior del ábside.

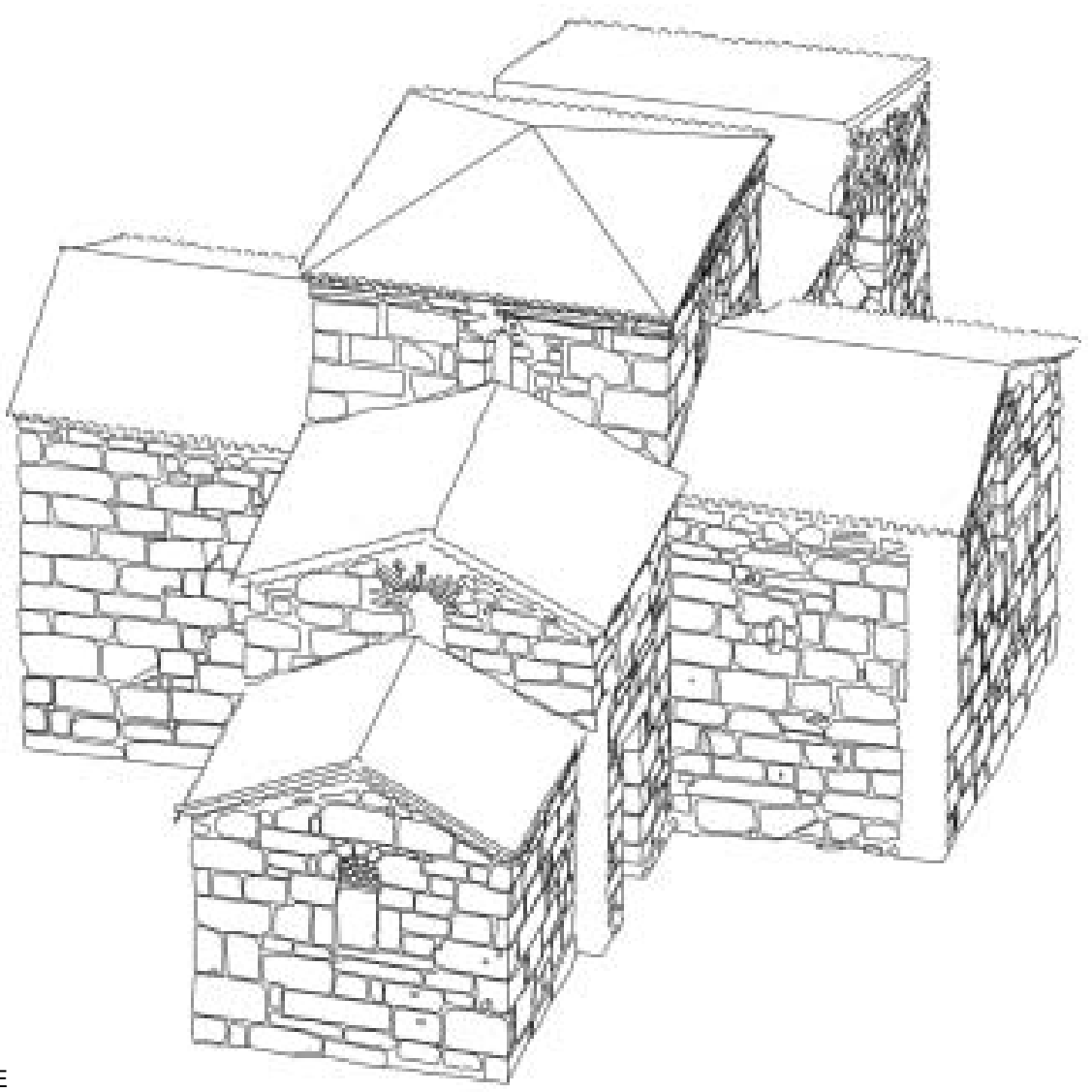




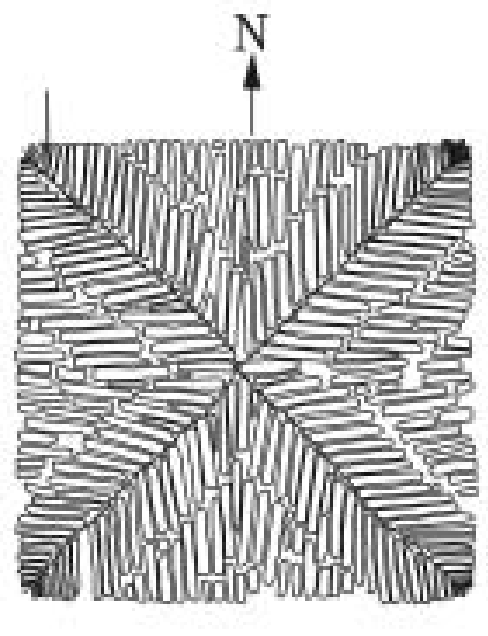

PLANTA

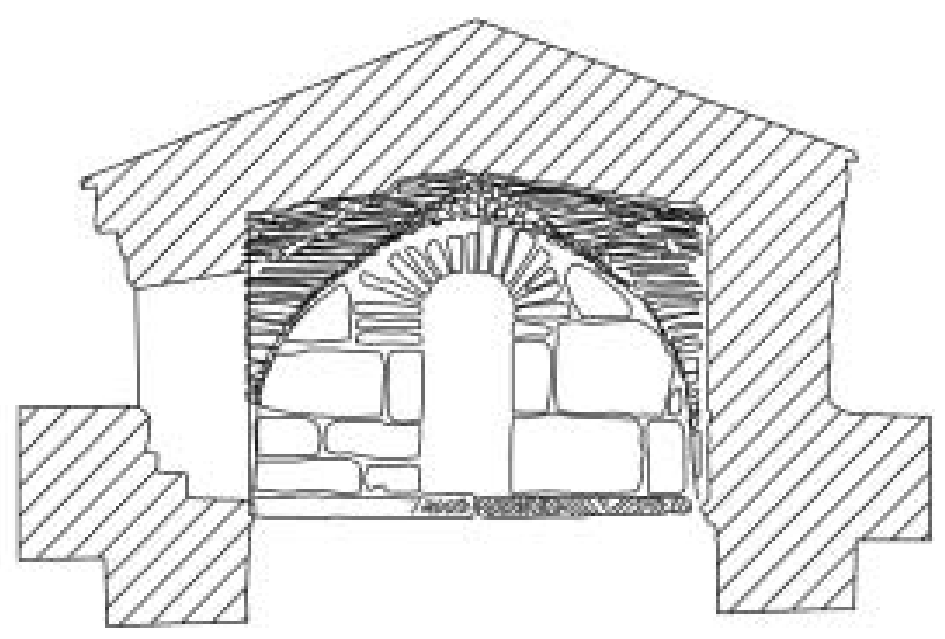

ALZADO SUR

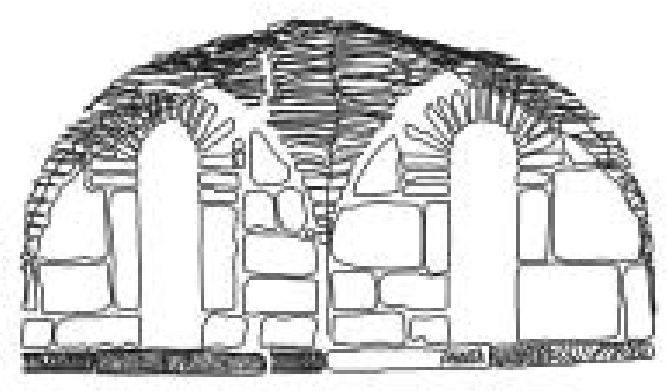

SBCCION DIAGONAL NE-SO

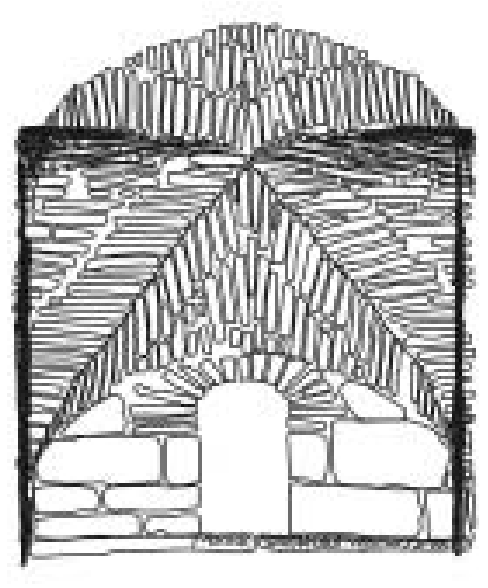

PERSPECTIVA SUR

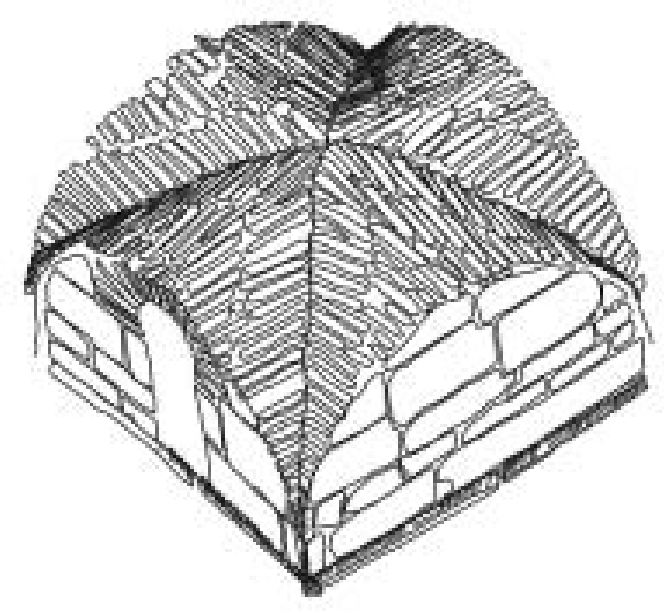

PERSPECTIVA SUR-OESTE

Escala 1:50

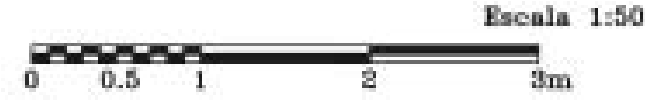

Fig. 3. Bóveda del cimborrio 
Etapa V. Época moderna. Como reza en una inscripción, en el siglo XVII se alzó la capilla funeraria suroccidental y se construyó, consecuentemente, una nueva portada para la iglesia. La sacristía noreste también se erigió en este momento, adosándose a los paramentos restaurados en etapas anteriores.

Etapa VI y VII. La adición de la espadaña en el siglo XIX fuerza el corte del arco norte del porche y el adosamiento del contrafuerte de este lado para contrarresto de su peso.

En el siglo $X X$ se acometen diferentes obras. Como atestiguan las fotografías conservadas, la capilla trasera debió demolerse a comienzos del siglo XX. Ya en la década de los treinta, el arquitecto Alejandro Ferrant lleva a cabo la restauración de la iglesia, la más determinante hasta nuestros días.

\section{LA ARQUEOLOGÍA EXPLICA EL GUIÓN}

La iglesia original. La lectura estratigráfica explica el guión histórico de un modo muy diferente a la teoría que sigue al pie de la letra el documento escrito. La iglesia original de Bande describe una planta cruciforme y está integrada por una fábrica unitaria que incluye muros de sillería reutilizada y bóvedas de ladrillo (Fig. 2 y 3). Las destrucciones y restauraciones sucesivas han afectado a las hojas exteriores de los muros, pero no a las interiores, lo que ha permitido la conservación de las estructuras abovedadas. De igual manera, la escultura decorativa (impostas de las bóvedas, friso del ábside, capiteles del arco de entrada al presbiterio) fue puesta en obra al mismo tiempo. Toda ella, a excepción de dos capiteles romanos reutilizados, está hecha ex profeso para la iglesia. Litúrgicamente, los espacios se organizaban gracias a la presencia de un cancel en la embocadura del ábside pavimentado con opus signinum, el cual conserva las huellas del altar original, y una cortina que colgaba del arco oriental del crucero y que cerraba el anteábside con la ayuda de otro cancel.

Tipológicamente, los paralelos decorativos y formales de Bande son altomedievales, en concreto asturianos y mozárabes: la imposta de granito sogueada, los dos capiteles de la embocadura del ábside y las bóvedas de ladrillo, las cuales encontramos también en las iglesias cercanas de Montelios y Celanova. Junto a las herramientas tradicionales, los análisis de termoluminiscencia de los ladrillos de las bóvedas datan el material en la segunda mitad del siglo VIII. Con ello se descarta el origen romano de los ladrillos, como se había propuesto tradicionalmente, pero la fecha resultante no se ajusta ni a la propuesta de una iglesia visigoda, ni al planteamiento de una iglesia de repoblación.

Replanteamiento de la historia de Santa Comba. Los datos aportados por la lectura del documento material entran en contradicción con la explicación histórica generada por el documento escrito. A partir de aquí el texto deja de ser una referencia fiable para conocer el origen y evolución de la iglesia. No se puede basar la historia de Santa Comba en una información de la que no ha sido valorada ni su génesis ni su transmisión: un texto moderno elaborado para prestigiar el pasado de un monasterio en horas bajas (San Miguel de Celanova) en el que se recogen documentos posiblemente interpolados siglos atrás para dirimir disputas de propiedad sobre las posesiones adscritas a la iglesia.

La valoración del documento escrito y de los caracteres formales, estructurales y decorativos de Bande acercan a la iglesia a una época posterior, cercana a la arquitectura asturiana del IX y descendiente del influjo oriental transmitido por el mundo omeya.

\section{Ficha técnica}

Xunta de Galicia (Dirección Xeral de Patrimonio Cultural de Consellería de Cultura e Comunicación Social) - CSIC (Instituto de Historia). Arquitectos, M. Seoane Feijoo, M. ${ }^{\mathrm{J} J}$. Blanco Piñeiro.

Equipo, L. Caballero Zoreda (director), F. Arce Sainz, F.J. Fernández de la Peña, A. Plata Montero, M. ${ }^{a}$ A. Utrero Agudo.

Septiembre 1999.

\section{Bibliografía}

Caballero Zoreda L., 1980, La iglesia y el monasterio visigodo de Santa María de Melque (Toledo). San Pedro de la Mata y Santa Comba de Bande, Excavaciones Arqueológicas en España, 109, Madrid.

Caballero Zoreda L., 1991, Sobre Santa Comba de Bande (Ourense) y las placas de Saamasas (Lugo), Galicia no tempo, pp. 96-106.

CAMÓn Aznar J., 1963, Arquitectura española del siglo x. Mozárabes y de repoblación, Goya, 52, pp. 206-19.

Camps Cazorla E., 1963 (1935), El arte hispano-visigodo, en MEnÉNDEZ PIDAL (dir.), Historia de España, III, Madrid.

Gómez Moreno M., 1943-44, Exploraciones en Santa Comba de Bande, Boletín de la Comisión de Monumentos de Orense, 14, pp. 47-51.

KIngSley K., 1980, Visigothic Architecture in Spain and Portugal: a study in masonry, documents and form, Berkeley.

NúÑez M., 1978, Arquitectura prerrománica, Historia da Arquitectura Galega, COAG.

Palol P., 1968, Arte hispánico de la época visigoda, Barcelona.

Palol P., Ripoll G., 1988, Los godos en el occidente europeo, Madrid.

PUIG I CADAFALCH J., 1961, L'art wisigothique et ses survivences: recherches sur les origins et le dévelopment de l'art en France et en Espagne du IVe au XIIe siècle, París.

Schlunk H., 1947, Arte visigodo, Ars Hispaniae, II, Madrid. 